\title{
Role of Nitric Oxide in Renal Medullary Oxygenation Studies in Isolated and Intact Rat Kidneys
}

\author{
Mayer Brezis, * Samuel N. Heyman, Dganit Dinour, Franklin H. Epstein, and Seymour Rosen \\ Department of Medicine, Hadassah University Hospital, Mount Scopus, Jerusalem, Israel; Departments of Medicine and Pathology,
} Beth Israel Hospital; and the Harvard Center for Kidney Diseases, Harvard Medical School, Boston, Massachusetts 02215

\begin{abstract}
We investigated the role of the endothelial-derived relaxing factor nitric oxide (NO) in the homeostasis of $\mathrm{O}_{2}$ supply to the renal medulla, a region normally operating on the verge of hypoxia. Sensitive Clark-type $\mathrm{O}_{2}$ microelectrodes were inserted into renal cortex and medulla of anesthetized rats. The inhibitor of NO formation, $\mathbf{L}-\boldsymbol{N}^{\mathbf{C}}$-monomethylarginine (LNMMA), while increasing blood pressure and reducing renal blood flow, decreased medullary $\mathrm{pO}_{2}$ from $23 \pm 3 \mathrm{mmHg}$ to $12 \pm 3$ (P $<0.001$ ), with no change in the cortex. These responses were promptly reversed by L-arginine, which bypasses the LNMMA blockade. In isolated rat kidneys, LNMMA reduced perfusion flow without altering glomerular filtration rate, and augmented deep medullary hypoxic injury to thick ascending limbs from 68 to $90 \%$ of the tubules $(P<0.02)$. These changes were prevented by $L$-arginine. Nitroprusside had a protective effect upon thick limb injury. Finally, in a previously reported model of radiocontrast nephropathy (1988. J. Clin. Invest. 82:401), LNMMA increased the severity of renal failure (final plasma creatinine from $2.3 \pm 2 \mathrm{mg} \%$ to $3.4 \pm 3, P<0.005)$ and the proportion of damaged thick limbs (from $24 \pm 6 \%$ to $53 \pm 9, P<0.01$ ).

Nitrovasodilatation may participate in the balance of renal medullary oxygenation and play an important role in the prevention of medullary hypoxic injury. (J. Clin. Invest. 1991. 88:390-395.) Key words: renal medulla • thick ascending limb • oxygen microelectrode $\bullet$ contrast medium $\bullet$ indomethacin
\end{abstract}

\section{Introduction}

Nitric oxide (NO), originating from the endothelial cell metabolism of $\mathrm{L}$-arginine, has been identified as a potent endothelialderived relaxing factor (1). Recent studies have shown a potential role for NO in renal hemodynamics (2-4), and indicated its presence in the renal medulla (5).

Previous observations have shown that an efficient urinary concentrating mechanism necessarily generates in the medulla a zone of relative hypoxia (6) which may, under certain circumstances, induce damage to the medullary thick ascending

Address correspondence and reprint requests to Dr. M. Brezis, Department of Medicine, Hadassah University Hospital, Mount Scopus, Jerusalem, P.O. Box 24035, Israel.

Received for publication 5 November 1990 and in revised form 22 February 1991.

1. Abbreviations used in this paper: GFR, glomerular filtration rate; LNMMA, L- $N^{\mathrm{G}}$-monomethylarginine; mTAL, medullary thick ascending limbs; $\mathrm{NO}$, nitric oxide; $\mathrm{TR}_{\mathrm{Na}}$, tubular reabsorption of sodium.

J. Clin. Invest.

(c) The American Society for Clinical Investigation, Inc.

0021-9738/91/08/0390/06 \$2.00

Volume 88, August 1991, 390-395 limbs (mTALs) (7). Injury to thick ascending limbs is related to transport activity, as inhibition of this transport reduces damage, probably by reducing oxygen demand (6). Analysis of these data logically led to the proposition of powerful regulatory mechanisms for medullary oxygen balance (8).

In this study, we sought to investigate the potential role of NO in the homeostasis of oxygen supply to the renal medulla using oxygen microelectrodes and/or morphological techniques in intact rats and isolated perfused kidneys.

\section{Methods}

\section{Animals}

Sprague-Dawley rats weighing $330-480 \mathrm{~g}$ were used for all experiments. Anesthesia was performed either with Inactin (Byk, Gulden Konstans, Germany; $100 \mathrm{mg} / \mathrm{kg}$ body weight) for the measurements of intrarenal oxygen tensions and for the isolated perfused kidney experiments, or with pentobarbital $(50 \mathrm{mg} / \mathrm{kg})$ for the in vivo model of radiocontrast nephropathy.

\section{Measurement of intrarenal oxygen tensions}

These experiments were designed to evaluate the potential role of nitric oxide by inhibition of its formation with $\mathrm{L}-N^{\mathrm{G}}$-monomethylarginine (LNMMA) (9) upon intrarenal oxygen tensions in vivo. Sensitive $\mathrm{O}_{2}$ glass microelectrodes of the Clark type, with fine $(5-15 \mu)$ tip, were purchased from Omega Technologies (Haifa, Israel) for whom they are hand made by Mr. E. Traube. These electrodes were polarized at -0.75 $\mathrm{V}$, a potential where a linear response is observed between $\mathrm{O}_{2}$ tension and current through the electrode, connected to a picoamperemeter and a recorder, and daily calibrated in saline at $37^{\circ} \mathrm{C}$ (with $100 \% \mathrm{~N}_{2}$ and with a mixture of $\mathrm{N}_{2}$ and $\mathrm{O}_{2}$ containing $12 \% \mathrm{O}_{2}$ ) at the start and end of each experiment. Electrode drift was $2 \pm 1$ and $1 \pm 0.4 \%$ $($ mean \pm SE) per hour for low and high calibration values, respectively.

The electrodes, mounted on micromanipulators, were inserted into the left kidney of rats under anesthesia, after tracheostomy and laparotomy, exposure, and mechanical fixation of the left kidney. The temperature of the kidney was monitored by a needle copper probe connected to a type $T$ thermocouple (Omega Engineering, Stamford, CT) and kept at $37^{\circ} \mathrm{C}$ with a heating lamp and dripping warm saline and mineral oil. The femoral vein and artery were catheterized with PE-50 catheters for infusion of normal saline with bovine serum albumin $(4.5$ $\mathrm{g} / \mathrm{dl}$ ) at a rate of $0.08 \mathrm{ml} / \mathrm{min}$ and for monitoring of the blood pressure by a pressure transducer.

The kidney was decapsulated to reduce tissue compression during the penetration of the microelectrodes. After advancing it into the renal parenchyma, the microelectrode was moved backward until any depression of the kidney surface at the site of entry had disappeared. After placement of the electrodes, initial readings were frequently low and/or unstable for the first 20-30 min of the experiment, possibly because of the surgical trauma to the animal and tissue distortion around the microelectrode. After this equilibration period and stabilization of the readings, the microelectrodes were usually left in the same position. Measurements were made after the recording had stabilized for at least 2-3 min as a single reading (or as a mean of several readings if periodic oscillations were present, as observed in some micropuncture sites). Under basal conditions, $\mathrm{pO}_{2}$ values obtained at different depths into 
the renal parenchyma are illustrated in Fig. 1. Data are from 52 rats, with an average of four measurements per animal obtained with one, two, or three electrodes in parallel in one or more positions (repositioning of an electrode was always followed by a new equilibration period until a stable reading was observed). As shown in Fig. 1, a steep decline in $\mathrm{pO}_{2}$ is observed around a depth of $3 \mathrm{~mm}$, corresponding to the outer medullary region. Medullary $\mathrm{pO}_{2}$, collected from micropuncture sites deeper than $3 \mathrm{~mm}$, averaged $27 \pm 2 \mathrm{mmHg}$; cortical $\mathrm{pO}_{2}$, collected from micropuncture sites more superficial than $2 \mathrm{~mm}$, averaged $50 \pm 2$ $\mathrm{mmHg}\left(P<0.0001\right.$, vs. medullary $\left.\mathrm{pO}_{2}\right)$. These values are comparable to data reported by others $(10,11)$.

In this study, two microelectrodes were placed at the respective depths of $1.6 \pm 0.1$ (cortical site) and $4.2 \pm 0.1 \mathrm{~mm}$ (medullary site) and left in place for the duration of the experiment. On several occasions, in order to verify the position of these micropuncture sites, the microelectrode was replaced at the end of an experiment by a hollow micropipette of similar shape, placed on the same micromanipulator, and inserted at the same depth. After injection of a small volume of India ink, the micropipette was removed and the kidney perfused fixed by perfusion of glutaraldehyde through the aorta (as detailed below). The cortical site of micropuncture was in the cortex; the medullary site was in the outer medulla, usually in the inner stripe.

In 16 rats, LNMMA (Calbiochem Corp., La Jolla, CA) diluted in normal saline was injected slowly (over 2-3 min. i.v.) at an average dose of $20 \pm 2 \mathrm{mg} / \mathrm{kg}$ body weight, as follows: $4 \mathrm{mg} / \mathrm{kg}(n=1), 15 \mathrm{mg} / \mathrm{kg}$ $(n=5), 20 \mathrm{mg} / \mathrm{kg}(n=8), 30 \mathrm{mg} / \mathrm{kg}(n=1)$, and $45 \mathrm{mg} / \mathrm{kg}(n=1)$. Results were pooled as responses appeared comparable over this dose range. In 11 rats, after a stable response to LNMMA was obtained for both blood pressure and intrarenal $\mathrm{pO}_{2}$, reversal of the LNMMA blockade was attempted by the intravenous administration of L-arginine (Sigma Chemical Co., St. Louis, MO) at a dose 2.5-3 times the dose of LNMMA, averaging $51 \pm 3 \mathrm{mg} / \mathrm{kg}$, diluted in normal saline.

In order to evaluate the specificity of the effects observed with LNMMA, the response to two different systemic and/or renal vasoconstrictors was studied in seven rats. Norepinephrine (Sigma Chemical Co.) was dissolved in normal saline with ascorbic acid $(1 \mathrm{mg} / \mathrm{dl})$ to prevent oxidation (12) and infused at doses ranging from 0.2 to 0.8 $\mu \mathrm{g} / \mathrm{kg} / \mathrm{min}$ (mean $0.7 \pm 0.04$ ) for an average duration of $2 \mathrm{~min}$. A total of 23 infusions were performed. Endothelin-1 (Penninsula Laboratories, Belmont, CA) was infused at incremental doses ranging from 10 to 320

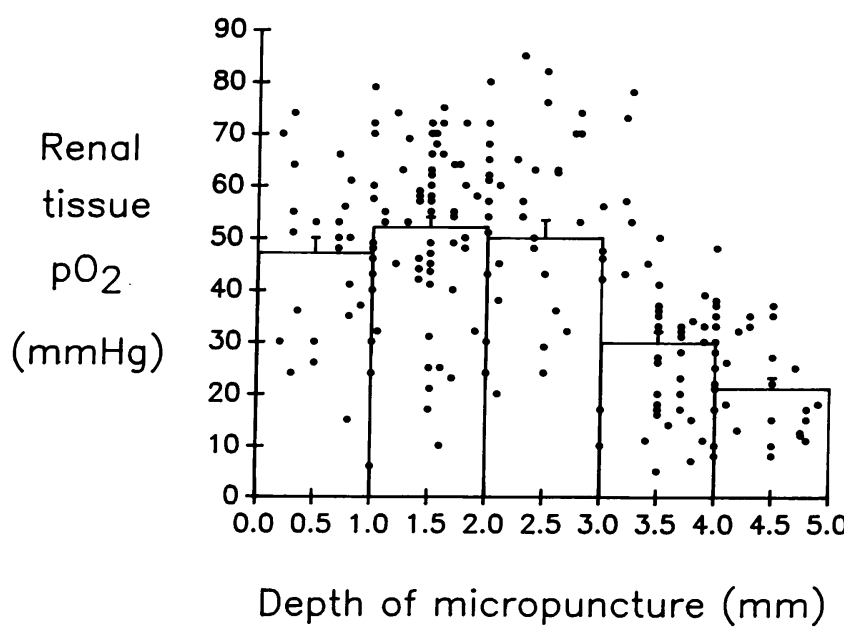

Figure 1. Renal tissue $\mathrm{pO}_{2}$ measured under basal conditions at different depths of micropuncture into kidney parenchyma. Vertical bars indicate mean $\pm \mathrm{SE}$ for values obtained at a depth of $0-1,1-2,2-3$, $3-4$, and 4-5 mm. Analysis of variance shows that $\mathrm{pO}_{2}$ readings at 3-4 and 4-5 $\mathrm{mm}$ are significantly lower than the $\mathrm{pO}_{2}$ recorded at any of the more superficial layers $(P<0.0001)$. Data are from kidneys in situ of 52 animals. pmol (mean 115 \pm 17 ) over an average duration of 4 min (range 1-22). A total of 24 infusions were performed. The wide range of doses used was designed to attempt to reproduce the changes in renal hemodynamics and oxygenation observed with LNMMA.

In five rats treated with LNMMA $(20 \mathrm{mg} / \mathrm{kg})$ and in the rats treated with other vasoconstrictors, renal blood flow was monitored by a pulsed Doppler method using a piezoelectric crystal mounted on the left renal artery (VF-1; Valpey-Fisher, Hopkinton, MA). Relative changes in flow velocity assessed by Doppler shift correlate well with the changes in renal blood flow measured by an electromagnetic flowmeter (13).

\section{Isolated perfused kidneys}

The purpose of these experiments was to evaluate the potential role of nitric oxide, by inhibition of its formation with LNMMA, upon the hemodynamics, the function, and the morphology of isolated perfused rat kidneys, a model known to show medullary vulnerability to oxygen deficiency (14).

Isolated rat kidneys were perfused in a closed circuit for $90 \mathrm{~min}$ with a recirculating Krebs albumin solution equilibrated with $95 \% \mathrm{O}_{2} / 5 \%$ $\mathrm{CO}_{2}$ and supplemented with glucose $5 \mathrm{mM}$, as in previous studies (14). Through each experiment the perfusion pressure at the tip of the cannula was kept constant at $85 \mathrm{mmHg}$. All perfusions were continued for $90 \mathrm{~min}$ before perfusion fixation with $1.25 \%$ glutaraldehyde for histological evaluation (see below). Experimental groups were as follows:

\section{CONTROL GROUPS $(n=18)$}

(a) Sodium acetate $(n=10)$. Because the acetate salt of LNMMA was used, sodium acetate was used in controls. Kidneys were perfused with sodium acetate added to the perfusate after $30 \mathrm{~min}$ of perfusion at the concentration of $3 \times 10^{-5} \mathrm{M}$.

(b) L-arginine and sodium acetate $(n=8)$. L-arginine was added at the concentration of $10^{-4} \mathrm{M}$ from the start of the perfusion. Sodium acetate was then added as in the previous group.

As the results of these groups did not differ at any time, they were pooled in a single control group for further analysis. Three kidneys were not available for histology because of improper fixation.

\section{LNMMA $(n=12)$}

LNMMA was added to the perfusate after $30 \mathrm{~min}$ of perfusion, at the final concentration of $3 \times 10^{-5} \mathrm{M}$. Two kidneys were not available for histology because of improper fixation.

III. L-ARGININE AND LNMMA $(n=6)$

$\mathrm{L}$-arginine was added at the concentration of $10^{-4} \mathrm{M}$, from the start of the perfusion, in an attempt to bypass the postulated inhibition of nitric oxide formation by LNMMA (15). LNMMA was then added to the perfusate after $30 \mathrm{~min}$ of perfusion, at the final concentration of 3 $\times 10^{-5} \mathrm{M}$.

IV. NITROPRUSSIDE $(n=9)$

Sodium nitroprusside is believed to induce vasodilatation by directly releasing nitric oxide from its nitroso moiety when in contact with tissues (16). In order to evaluate the effect of direct nitrovasodilatation, sodium nitroprusside (Sigma Chemical Co.) was added to the perfusate at the final concentration of $10^{-4} \mathrm{M}$ followed by a constant infusion of $3 \mu \mathrm{g} / \mathrm{min}$. Nitroprusside is an unstable molecule that decomposes when exposed to light and when in contact with the vascular wall (16). The maintenance infusion was designed empirically to replace $10 \%$ of the initial amount of nitroprusside during the course of a 90-min experiment. Because these experiments were performed in a different laboratory, a separate group of controls was used. In these experiments the perfusion pressure at the tip of the cannula was kept constant at 100 $\mathrm{mmHg}$.

\section{In vivo model of acute renal failure}

The purpose of these experiments was to determine the effects of inhibition of nitric oxide formation in vivo by LNMMA upon renal function 
and morphology in a previously described model of acute renal failure with medullary hypoxic lesions (7). In brief, after left uninephrectomy, rats were salt depleted with furosemide $(2 \mathrm{mg} / \mathrm{kg})$ followed by a low salt diet for a week. 60 min after a single injection of indomethacin (10 $\mathrm{mg} / \mathrm{kg}$, i.v.), sodium iothalamate, $80 \%$ (Angio-Conray; Mallinckrodt, Inc., St. Louis, MO), was administered through the femoral artery at the dosage of $6 \mathrm{ml} / \mathrm{kg}$ body weight. A total of 34 rats received this protocol of renal failure with LNMMA treatment $(n=12)$ or without $(n=22)$. LNMMA dissolved in saline $(15 \mathrm{mg} / \mathrm{ml})$ was given as a single intravenous bolus injection $(15 \mathrm{mg} / \mathrm{kg}) 10 \mathrm{~min}$ before the administration of the contrast media. Blood pressure was monitored in all the LNMMA-treated rats to confirm a systemic hemodynamic effect, with the use of a pressure transducer and monitor (Hewlett-Packard, Inc., Sunnyvale, CA) mounted on the femoral arterial line.

Functional studies. The rats were kept in metabolic cages (Nalge Co., Rochester, NY) $24 \mathrm{~h}$ before (day 0 ) and after the experiment (day 1). Blood and urine samples from 24-h collections were taken at baseline and at the end of day 1 for the determination of creatinine clearances and fractional excretions of electrolytes.

Morphologic studies. Rats were killed $24 \mathrm{~h}$ after the injection of the radiologic contrast material for morphologic evaluation. Under anesthesia, in vivo renal fixation perfusion, with $1.25 \%$ glutaraldehyde (Eastman Kodak Co., Rochester, NY) in $0.1 \mathrm{M}$ phosphate buffer (pH 7.4), was performed through a 19-gauge needle inserted in the aorta. Perfusion pressure was kept constant at $140 \mathrm{mmHg}$.

The kidneys from both in vitro and in vivo experiments were sliced and postfixed in buffered $2 \% \mathrm{OsO}_{4}$, dehydrated, and embedded in an araldite-Epon 812 mixture. $3 \times 3-\mathrm{mm}$ sections were cut, containing cortex and outer medulla. Stained with $1 \%$ methylene blue, the sections were examined in a blinded fashion as previously described $(6,14)$. In the inner stripe of the outer medulla, damaged mTALs were counted and expressed as a percentage of the total number of tubules present. Moderate damage was defined by the presence of blatant mitochondrial swelling with limited nuclear pyknosis. Severe damage was defined by the presence of extensive nuclear pyknosis and cell fragmentation (14).

\section{Statistical analysis}

Data are presented as mean $\pm \mathrm{SE}$. Analysis of variance was used to compare different groups and repeated measures with a posthoc test (Scheffe).

\section{Results}

1. Measurement of intrarenal oxygen tensions. The effects of inhibition of nitric oxide formation with LNMMA upon intrarenal oxygenation are illustrated in Fig. 2. As previously observed (15), the administration of LNMMA was associated

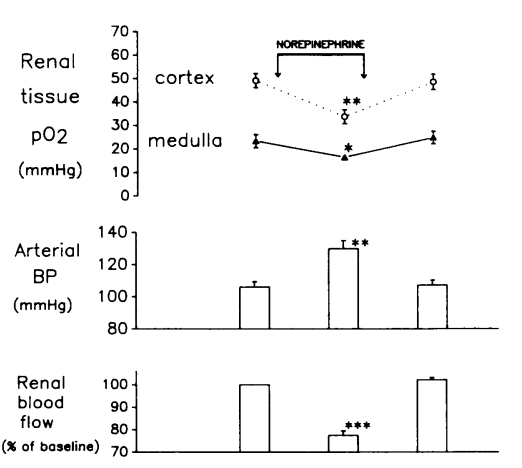

Figure 3. Effects of infusion of norepinephrine upon intrarenal oxygen tension, systemic blood pressure, and renal blood flow. Values are baseline, after $\sim 2$ min of norepinephrine infusion and 5-10 min after the end of this infusion. Statistical significance refers to comparison with corresponding baseline and final values (ANOVA). ${ }^{*} P$ $<0.001,{ }^{* *} P<0.0001$, *** $P<0.001$.

with a rise in blood pressure, which was reversed by the additional administration of $\mathrm{L}$-arginine. LNMMA induced a reduction in medullary $\mathrm{pO}_{2}$ (from $23 \pm 3$ to $12 \pm 3 \mathrm{mmHg}, P<0.001$, ANOVA and Scheffe's test), which was reversed by L-arginine. No significant change occurred in the cortex, except for a transient decrease in $\mathrm{pO}_{2}$ sometimes observed during the injection of LNMMA. As shown by others (3), the administration of LNMMA was associated with a $25 \%$ reduction in renal blood flow, which was reversed by $L$-arginine.

Fig. 3 illustrates the average effects of norepinephrine upon intrarenal oxygenation. Norepinephrine induced a rise in blood pressure and a $22 \%$ reduction in renal blood flow. In contrast to the experiments with LNMMA, these changes were associated with marked reductions in cortical as well as medullary $\mathrm{pO}_{2}$. At all doses tested, a decline in medullary $\mathrm{pO}_{2}$ was always accompanied by a decline in cortical $\mathrm{pO}_{2}$.

Fig. 4 illustrates the average effects of endothelin upon intrarenal oxygenation. Endothelin induced a $30 \%$ reduction in renal blood flow without altering systemic blood pressure. These changes were associated with a reduction in cortical $\mathrm{pO}_{2}$ and a small increase in medullary $\mathrm{pO}_{2}$. Unlike the experiments with LNMMA, a selective decrease in medullary $\mathrm{pO}_{2}$ was not observed in any experiment.

2. Isolated perfused kidneys. Fig. 5 illustrates the effects of inhibition of nitric oxide formation with LNMMA upon perfusion flow of isolated rat kidneys. Vasoconstriction was ob-

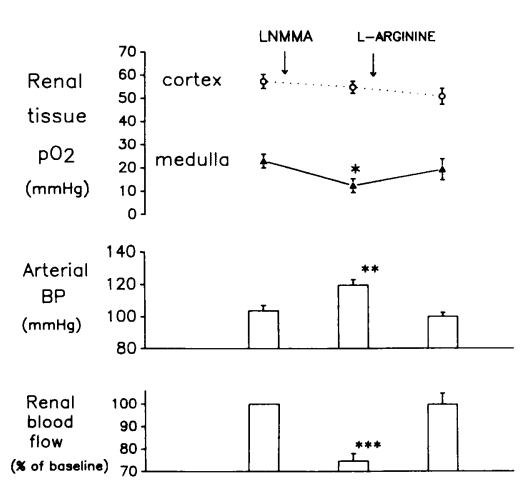

Figure 2. Effects of inhibition of nitric oxide formation with LNMMA upon intrarenal oxygen tension, systemic blood pressure, and renal blood flow. Values are baseline, 5-10 min after LNMMA and 5-10 min after L-arginine. Statistical significance refers to comparison with corresponding baseline and final values (ANOVA). ${ }^{*} P<0.001,{ }^{* *} P$ $<0.0001,{ }^{* * *} P<0.005$.

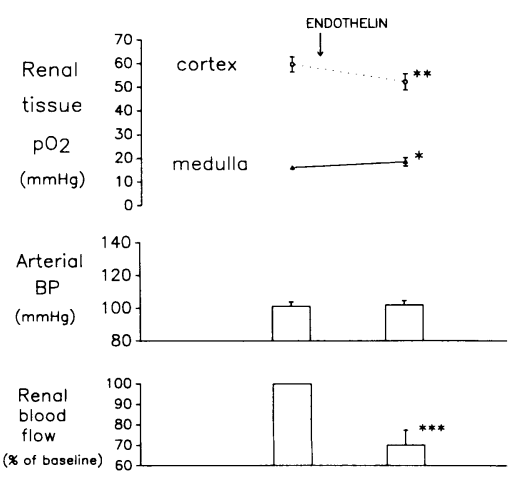

Figure 4. Effects of infusion of endothelin upon intrarenal oxygen tension, systemic blood pressure, and renal blood flow. Values are baseline and after an average of $5 \mathrm{~min}$ after endothelin administration. Statistical significance refers to comparison with corresponding baseline value (ANOVA). Recovery is not shown as it was often incomplete. ${ }^{*} P<0.05$, ${ }^{* *} P<0.001,{ }^{* * *} P$ $<0.001$. 
Table I. Effects of LNMMA, L-arginine, and Nitroprusside on Function of Isolated Perfused Kidneys

\begin{tabular}{ccccc}
\hline $\begin{array}{c}\text { Experimental } \\
\text { group }\end{array}$ & $\mathrm{GFR}$ & $\mathrm{TR}_{\mathrm{N}}$ & $\mathrm{Fe}_{\mathrm{K}}$ & $\begin{array}{c}\text { Perfusate } \\
\text { flow }\end{array}$ \\
\hline $\begin{array}{c}\text { Controls } \\
(n=18)\end{array}$ & $0.45 \pm 0.04$ & $95 \pm 0.7$ & $78 \pm 6$ & $44.8 \pm 1.9$ \\
$\begin{array}{c}\text { LNMMA } \\
(n=12)\end{array}$ & $0.42 \pm 0.03$ & $94 \pm 1.0$ & $79 \pm 5$ & $32.2 \pm 1.7^{*}$ \\
$\begin{array}{c}\text { LNMMA } \\
\quad+\text { L-arginine } \\
(n=6)\end{array}$ & $0.42 \pm 0.03$ & $95 \pm 0.5$ & $74 \pm 5$ & $40.5 \pm 1.5$ \\
$\begin{array}{c}\text { Controls } \\
(n=16)\end{array}$ & $0.42 \pm 0.02$ & $93 \pm 0.8$ & $107 \pm 8$ & $42.9 \pm 1.4$ \\
$\begin{array}{c}\text { Nitroprusside } \\
(n=9)\end{array}$ & $0.41 \pm 0.03$ & $92 \pm 1.3$ & $82 \pm 1.3$ & $38.1 \pm 1.6$ \\
\hline
\end{tabular}

Data are mean $\pm \mathrm{SE}$ at 60 min of perfusion. $\mathrm{Fe}_{\mathrm{K}}$, fractional excretion of potassium. ${ }^{*} P<0.001$ vs. adjacent groups.

served within minutes, becoming significant at $10 \mathrm{~min}$, with flow reaching a minimum at 20-30 min after the addition of LNMMA and persisting at $\sim 70 \%$ of baseline thereafter. This effect was largely prevented by previous addition of $\mathrm{L}$-arginine. Table I summarizes the renal function of the isolated kidneys perfused with or without LNMMA. Glomerular filtration rate (GFR), tubular reabsorption of filtered sodium $\left(T R_{\mathrm{Na}}\right)$, and fractional excretion of potassium $\left(\mathrm{Fe}_{\mathrm{K}}\right)$ were not significantly altered by LNMMA. Filtration fraction was increased at 60 min of perfusion, from $1.04 \pm 0.09 \%$ in controls to $1.33 \pm 0.10 \%$ $(P<0.05)$ with LNMMA.

Fig. 6 indicates the effect of LNMMA upon the injury induced by medullary hypoxia in isolated perfused kidneys. Under control conditions, $\sim 70 \%$ of medullary thick ascending limbs showed tubular damage in the deepest regions of the inner stripe. LNMMA extended this injury to almost $90 \%$ of tubules. This effect was prevented by preaddition of $\mathrm{L}$-arginine.

Nitroprusside reduced severe mTAL injury in the inner stripe of the outer medulla by nearly half (Fig. 7). No significant changes were seen in GFR, total renal perfusate flow, or fractional excretion of sodium or potassium (Table I).

3. In vivo model of acute renal failure. Fig. 8 illustrates the effects of LNMMA in a model of acute renal failure associated with radiocontrast administration. The administration of LNMMA aggravated both renal failure and injury to mTALs. With LNMMA, creatinine clearance decreased from

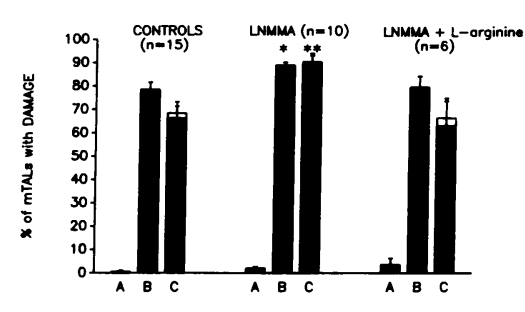

Figure 6. Effect of inhibition of nitric oxide formation with LNMMA upon hypoxic injury to mTAL in isolated perfused kidneys. $A, B$, and $C$ are regions in the inner stripe (outer, mid, and inner); severe damage (a), moderate damage (). ${ }^{*} P<0.05$ vs. controls, ${ }^{* *} P<0.05$ vs. any other group.

$0.17 \pm 0.01 \mathrm{ml} / \mathrm{min}$ per $100 \mathrm{~g}$ body weight at baseline to $0.03 \pm 0.01(P<0.002)$ the day after radiocontrast administration, significantly more than without LNMMA (from $0.24 \pm 0.03$ to $0.08 \pm 0.01, P<0.001), P<0.005$ for the comparison between final creatinine clearances. Tubular dysfunction was also more pronounced with LNMMA, as the $T_{R_{\mathrm{Na}}}$ declined from $99.9 \pm 0.0 \%$ at baseline to $97.1 \pm 0.7(P<0.01)$, significantly worse than without LNMMA (from $99.9 \pm 0.0$ to 98.7 $\pm 0.2, P<0.001), P<0.05$ for the comparison of final $\mathrm{TR}_{\mathrm{Na}}$ between the two groups.

\section{Discussion}

Recent studies have demonstrated an important role for nitric oxide as an endothelial-derived relaxing factor in the regulation of both systemic and regional vascular resistances $(2,3,15,17)$. This work was designed to assess the role of nitrovasodilatation in the homeostasis of intrarenal oxygen supply to the renal medulla, a region normally operating on the verge of hypoxia (6) and therefore likely to have strong vasodilatory mechanisms. The general scheme of these experiments was to study the effect of LNMMA, a specific inhibitor of the formation of nitric oxide from L-arginine (9), first upon measured intrarenal cortical and medullary $\mathrm{O}_{2}$ tensions, then upon the extent of medullary hypoxic injury observed in isolated perfused kidneys, and finally in a model of acute renal failure associated with radiocontrast administration. An excess of $L$-arginine was used to compete for LNMMA and bypass its inhibition of nitric oxide release $(9,18)$

As indicated in Fig. 2, LNMMA induced a significant reduction in medullary $\mathrm{pO}_{2}$, which was almost entirely reversed by L-arginine, suggesting that nitric oxide may normally participate in renal vasodilation with a preferential effect within the medullary vasculature. The specificity of the effect observed with LNMMA upon intrarenal oxygenation is suggested by the

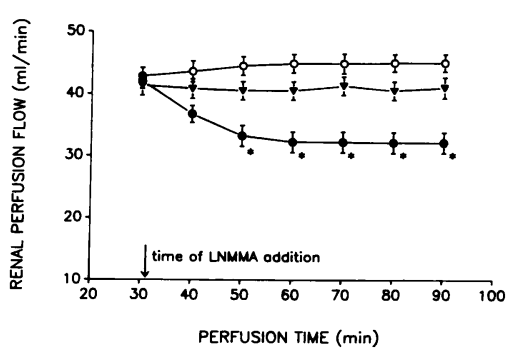

Figure 5. Effects of inhibition of nitric oxide formation with LNMMA upon perfusion flow of isolated rat kidneys. Controls (O) $(n=18)$, LNMMA with L-arginine $(\nabla)(n=6)$, LNMMA $(\bullet)(n=12)$. ${ }^{*} P<0.001$ vs. other groups or baseline.

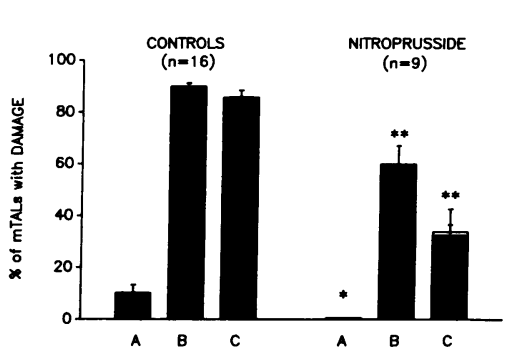

Figure 7. Effect of nitroprusside upon hypoxic injury to $\mathrm{mTAL}$ in isolated perfused kidneys. $A, B$, and $C$ are regions in the inner stripe (outer, mid, and inner); severe damage (ם), moderate damage (). ${ }^{*} P<0.005,{ }^{* *} P$ $<0.0005$. 

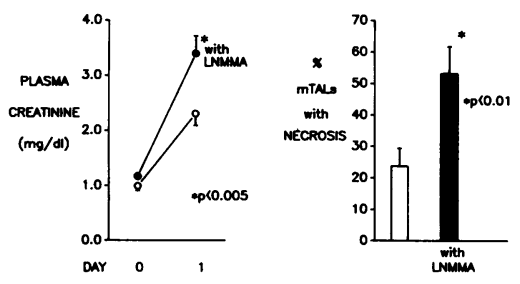

Figure 8. Effects of inhibition of nitric oxide formation with LNMMA in radiocontrast-associated acute renal failure in the rat.

experiments conducted with other vasoconstrictors. Comparable reductions in renal blood flow elicited by either norepinephrine or endothelin-1 did not reproduce the selective decrease in medullary $\mathrm{pO}_{2}$ observed with LNMMA (Figs. 3 and 4). Norepinephrine appeared to lead to a disproportionate reduction in cortical $\mathrm{pO}_{2}$, potentially related to an increase in transport activity and oxygen consumption in the proximal tubules (19). Endothelin-1 appeared to induce a small increase in medullary $\mathrm{pO}_{2}$, possibly related to markedly decreased GFR, tubular solute delivery, and oxygen demand for reabsorption (20). Although the exact mechanisms for these findings cannot be determined from this study, renal vasoconstriction does not appear in itself to produce selective medullary hypoxemia.

The differential effect of LNMMA in cortex and medulla might theoretically have several explanations. Nitric oxide released by endothelial cells stimulates the guanylate cyclase in adjacent vascular smooth muscle cells, increasing intracellular cyclic GMP and inducing vessel wall relaxation $(21,22)$. Medullary blood flow is supplied through juxta-medullary glomeruli (23). In both afferent and efferent arterioles of these glomeruli, smooth muscle structures are more developed than in their counterparts in superficial glomeruli $(23,24)$. In some species (including the rat), intraarterial cushions made of smooth muscle cells covered by endothelium, present in deep afferent arterioles (and not in superficial), have been suggested to play an important role in the regulation of medullary blood flow (23). In all mammalian kidneys studied, juxtamedullary efferent arterioles are longer and contain more smooth muscle cells than those higher in the cortex $(23,24)$. Descending vasa recta are also enveloped by smooth muscle cells in their proximal portions, and more distally are encircled by pericytes capable of contractile function (24). This abundance of smooth muscle cells along the medullary vasculature, flanked by a vast surface of endothelial cells within the vasa recta, could therefore represent an important site for nitric oxide release and action. Nitric oxide production might indeed be especially high in the renal medulla (5). Of interest is how the kidney produces arginine along the convoluted and the straight portion of the proximal tubule (25). As recently demonstrated for other amino acids (26), it is conceivable that arginine is concentrated and recycled in the medulla, providing an important precursor for the local synthesis of nitric oxide (18). Alternatively, the medullary vessels may be more responsive to nitrovasodilatation than cortical vessels. Preliminary experiments have shown that a systemic hypotensive infusion of nitroprusside increases medullary $\mathrm{pO}_{2}$ (unpublished results). This could, however, represent a corticomedullary shift of blood flow, a nonspecific response to hypotension. Medullary vasodilatation has been observed in response to acetycholine and bradykinin, both known to stimulate the endogenous production of nitric oxide (22), but not in response to another renal vasodilator, secretin (27). Finally, it is conceivable that cortex and medulla vessels are equally responsive to inhibition of nitric oxide formation. Tissue oxygen tensions might, however, have been more readily affected by vasoconstriction in zones of poor oxygen supply and high oxygen demand such as the renal medulla than in zones flooded with oxygen by high blood flow such as the renal cortex (6). Regardless of its precise mechanism, the preferential effect of nitrovasodilatation upon renal medullary oxygenation could have pathophysiological implications, as shown in the subsequent sets of experiments.

In the isolated perfused kidney, LNMMA reduced perfusion flow (at constant perfusion pressure) without altering GFR, thus raising filtration fraction. As shown in Fig. 6, LNMMA extended the fraction of medullary tubules involved by hypoxic injury in this model (14). The increased mTAL damage most probably reflects a greater imbalance between oxygen demand and supply when GFR and distal tubular reabsorption are maintained while at the same time delivery of oxygen is curtailed. Such a relationship between overall renal filtration function and medullary oxygen balance had been previously suggested in the isolated perfused kidney exposed to angiotensin II (28). In this study, the effects of LNMMA were prevented in the presence of an excess of $L$-arginine, supporting the relationship of these effects to inhibition of nitric oxide production. Furthermore, nitroprusside reduced medullary hypoxic injury (Fig. 7), suggesting that nitrovasodilatation improves medullary oxygenation. Nitroprusside, $10^{-4} \mathrm{M}$, did not alter the respiration of dispersed mTAL tubules (unpublished results). Taken together, these experiments suggest that blocking intrarenal endothelial-derived relaxation may endanger medullary oxygen balance.

The last set of experiments was designed to test whether inhibition of nitric oxide production in vivo might indeed aggravate medullary hypoxic injury in circumstances already associated with undue perturbation of medullary oxygenation. The model chosen was a prototype of radiocontrast-induced acute renal failure using multiple combined insults apparently necessary to impair medullary homeostasis and uncover medullary hypoxic injury associated with overall renal dysfunction (7). The addition of LNMMA before the injection of radiocontrast material, both aggravated the degree of kidney failure and extended the proportion of mTALs involved with necrosis (Fig. 8). These data suggest that interference with endothelialderived relaxation within the kidney may predispose the medullary region to intense hypoxic injury associated with severe renal failure.

These results may be relevant to the phenomenon of renal failure associated with hemolysis or rhabdomyolysis. Nitric oxide binds tightly to the heme moieties of these proteins, and free hemoglobin is a powerful inhibitor of endothelial-mediated vasorelaxation (29). In preliminary experiments, an infusion of myoglobin induced a selective decrease in medullary $\mathrm{pO}_{2}$ (unpublished data). Accumulation of heme-containing proteins in the kidney, with consequent blockage of endogenous nitric oxide-induced vasodilatation, may contribute to the pathogenesis of pigment nephropathy.

A number of studies have demonstrated an abundance of vasoregulatory substances active at the medullary vasculature, as evidenced by a high local concentration of the substance itself or of its receptors. Thus, both vasodilator agents such as prostaglandins (30) and adenosine (31), and vasoconstrictor agents such as angiotensin (32) and endothelin (33), appear to converge on this zone of the kidney, possibly in order to regulate medullary blood flow, so critical for optimal urinary con- 
centration as well as for precise control of medullary oxygenation (8). Because hypoxia is a potent stimulus for the release of nitric oxide (21), nitrovasodilatation would be a logical regulatory factor in the delicate balance of medullary oxygen supply and demand, and may play an important role in the prevention of medullary hypoxic injury.

\section{Acknowledgments}

The authors are grateful to Ms. Ahuva Shina, Lena Ellezian, and Kate Spokes for their excellent technical assistance, and to Dr. P. Silva and Mr. R. Fuhro for the experiments with isolated, dispersed medullary tubules.

This work was supported by grants from the USA-Israel Binational Science Foundation and the National Institutes of Health (DK-39249 and DK-18078).

\section{References}

1. Palmer, R. M., D. S. Ashton, and S. Moncada. 1988. Vascular endothelial cells synthesize nitric oxide from L-arginine. Nature (Lond.). 333:664-666.

2. Radermacher, J., U. Fostermann, and J. Frolich. 1990. Endothelium-derived relaxing factor influences renal vascular resistance. Am. J. Physiol. 259:F9F17.

3. Gardiner, S. M., A. M. Compton, T. Bennett, R. M. J. Palmer, and S. Moncada. 1990. Control of regional blood flow by endothelium-derived nitric oxide. Hypertension (Dallas). 15:486-492.

4. Tolins, J. P., R. M. Palmer, S. Moncada, and L. Raij. 1990. Role of endothelium-derived relaxing factor in regulation of renal hemodynamic responses. $\mathrm{Am}$. J. Physiol. 258:H655-H662.

5. Biondi, M. L., P. M. Vanhoutte, and J. C. Romero. 1990. Endotheliumderived relaxing factor (EDRF) in renal medulla. Kidney Int. 37:364(a.) (Abstr.)

6. Brezis, M., S. Rosen, P. Silva, and F. H. Epstein. 1984. Renal ischemia: a new perspective. Kidney Int. 26:375-383.

7. Heyman, S. N., M. Brezis, C. A. Reubinoff, Z. Greenfeld, C. Lechene, F. H. Epstein, and S. Rosen. 1988. Acute renal failure with selective medullary injury in the rat. J. Clin. Invest. 82:401-412.

8. Brezis, M., S. Rosen, and F. H. Epstein. 1989. The pathophysiological implications of medullary hypoxia. Am. J. Kidney Dis. 13:253-258.

9. Rees, D. D., R. M. J. Palmer, H. F. Hodson, and S. Moncada. 1989. A specific inhibitor of nitric oxide formation from L-arginine attenuates endothelium-dependent relaxation. Br. J. Pharmacol. 96:418-424.

10. Leichtweiss, H. P., D. W. Lubbers, C. H. Weiss, H. Baumgartl, and W. Reschke. 1969. The oxygen supply of the rat kidney: measurements of intrarenal $\mathrm{pO}_{2}$. Pflugers Arch. 309:328-349.

11. Schurek H. J., U. Jost, H. Baumgärtl, H. Bertram, and U. Heckmann. 1990. Evidence for a preglomerular oxygen diffusion shunt in rat renal cortex. Am. J. Physiol. 259:F910-F915.

12. Kleinjans, J. C. S., J. F. M. Smits, H. Van Essen, G. M. Kasbergen, and H. A. J. Struyker Boudier. 1984. Hemodynamic characterization of hypertension induced by chronic intrarenal or intravenous infusions of norepinephrine in conscious rats. Hypertension (Dallas). 6:689-699.

13. Haywood, J. R., R. A. Shaffer, C. Fastenow, G. D. Fink, and M. J. Brody. 1981. Regional blood flow measurement with pulsed Doppler flowmeter in conscious rat. Am. J. Physiol. 241:H273-H278.
14. Brezis, M., S. Rosen, P. Silva, and F. H. Epstein. 1984. Selective vulnerability of the medullary thick ascending limb to anoxia in the isolated perfused kidney. J. Clin. Invest. 73:182-190.

15. Rees, D. D., R. M. Palmer, and S. Moncada. 1989. Role of endotheliumderived nitric oxide in the regulation of blood pressure. Proc. Natl. Acad. Sci. USA. 86:3375-3378.

16. Gerber, J. G., and A. S. Nies. 1990. Antihypertensive agents and the drug therapy of hypertension. In Goodman and Gilman's The Pharmacological Basis of Therapeutics. A. G. Gilman, L. S. Goodman, T. W. Rall, A. S. Nies, and P. Taylor, editors. Pergamon Press Inc., Elmsford, New York. 803-804.

17. Lahera, V., M. G. Salom, M. J. Fiksen-Olsen, L. Raij, and J. C. Romero. 1990. Effects of $\mathrm{N}^{\mathrm{G}}$-monomethyl-L-arginine and L-arginine on acetyl-choline renal response. Hypertension (Dallas). 15:659-663.

18. Sakuma, I., D. J. Stuehr, S. S. Gross, C. Nathan, and R. Levi. 1988. Identification of arginine as a precursor of endothelium-derived relaxing factor. Proc. Natl. Acad. Sci. USA. 85:8664-8667.

19. Beach, R. E., S. J. Schwab, P. C. Brazy, and V. W. Dennis. 1987. Norepinephrine increases $\mathrm{Na}^{+}-\mathrm{K}^{+}$-ATPase and solute transport in rabbit proximal tubules. Am. J. Physiol. 252:F215-F220.

20. Badr, K. F., J. J. Murray, M. D. Breyer, K. Takahashi, T. Inagami, R. C. Harris, M. Schwartzberg, and J. Ebert. 1989. Mesangial cell, glomerular, and renal vascular responses to endothelin in the rat kidney. J. Clin. Invest. 83:336342.

21. Brenner, B. M., J. L. Troy, and B. J. Ballermann. 1989. Endothelium-dependent vascular responses. Mediators and mechanisms. J. Clin. Invest. 84:1373-1378.

22. Vane, J. R., E. E. Anggard, and R. M. Botting. 1990. Regulatory functions of the vascular endothelium. $N$. Engl. J. Med. 323:27-36.

23. Pallone, T. L., C. R. Robertson, and R. L. Jamison. 1990. Renal medullary circulation. Physiol. Rev. 70:885-920.

24. Chou, S. Y., J. G. Porush, and P. F. Faubert. 1990. Renal medullary circulation: hormonal control. Kidney Int. 37:1-13.

25. Levillain, O., A. Hus-Citharel, F. Morel, and L. Bankir. 1990. Localization of arginine synthesis along rat nephron. Am. J. Physiol. 259:F916-F923.

26. Dantzler, W. H., and S. Silbernagl. 1988. Amino acid transport by juxtamedullary nephrons: distal reabsorption and recycling. Am. J. Physiol. 255:F397-F407.

27. Fadem, S. Z., G. Hernandez-Llamas, R. V. Patak, S. G. Rosenblatt, M. D. Lifschitz, and J. H. Stein. 1982. Studies on the mechanism of sodium excretion during drug-induced vasodilatation in the dog. J. Clin. Invest. 69:604-610.

28. Brezis, M., Z. Greenfeld, A. Shina, and S. Rosen. 1990. Angiotensin II augments medullary hypoxia and predisposes to acute renal failure. Eur. J. Clin. Invest. 20:199-207.

29. Ignerro, L. J., R. E. Byrns, G. M. Buga, and K. S. Wood. 1987. Endothelium-derived relaxing factor from pulmonary artery and vein possesses pharmacologic and chemical properties identical to those of nitric oxide radical. Circ. Res. 61:866-879.

30. Eriksen, E. F., B. Richelsen, B. P. Gesser, N. O. Jacobsen, and K. Stengaard-Pedersen. 1987. Prostaglandin $\mathrm{E}_{2}$ receptors in the rat kidney. Biochemical characterization and localization. Kidney Int. 32:181-186.

31. Brines, M. L., and J. N. Forrest. 1988. Autoradiographic localization of $A_{1}$ adenosine receptors to tubules in the red medulla and papilla of the rat kidney. Kidney Int. 33:256a. (Abstr.)

32. Mendelsohn, F. A. O., M. Millan, R. Quirion, G. Aguilera, S. T. Chou, and K. J. Catt. 1987. Localization of angiotensin II receptors in rat and monkey kidney by in vitro autoradiography. Kidney Int. 31:S40-S44.

33. MacCumber, M. W. C. A. Ross, B. M. Glaser, and S. H. Snyder. 1989. Endothelin: visualization of mRNAs by in situ hybridization provides evidence for local action. Proc. Natl. Acad. Sci. USA. 86:7285-7289. 